\title{
Popular Science Articles and Academic Reports on the Topics of Cultural Commodification and Institutionalised Racism
}

\author{
K.C.P. Vowles-Sørensen $\otimes$
}

The first creative piece, Not just Panna Cotta: "Bush Tucker" and Cultural foods in MasterChef Australia for 10th Series', is modeled on review-style articles in the British newspaper The Independent. The second creative piece, 'Tradition of 'Zwarte Piet' Racism or a Harmless Children's Celebration?', is modeled on op-ed-style articles in the British newspaper The Guardian. 


\section{Not just Panna Cotta: 'Bush Tucker' and Cultural foods in MasterChef Australia for 10th Series}

Kate Vowles-Sørensen | Aarhus | 2018

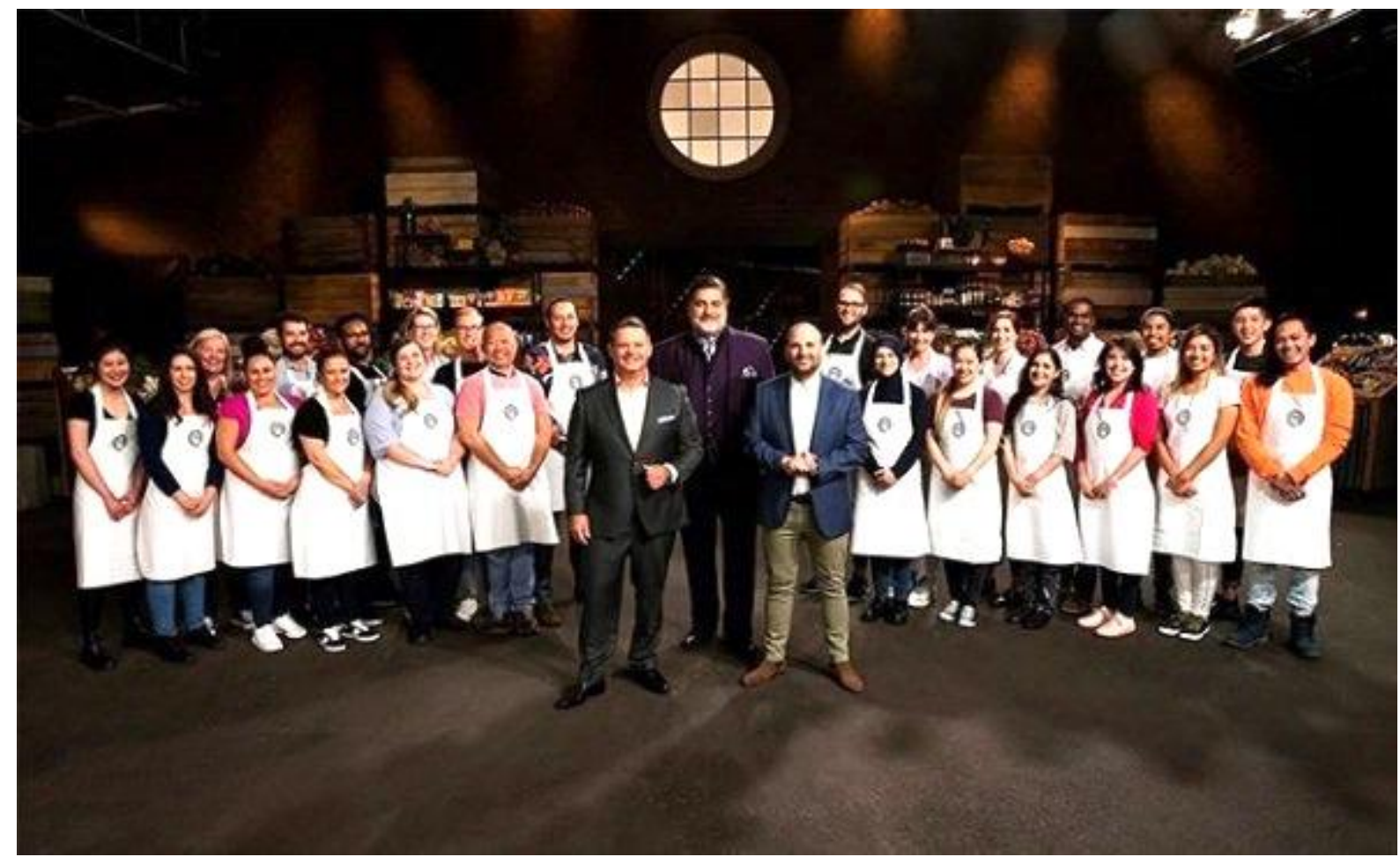

MasterChef Australia (2018)

For its tenth anniversary series, MasterChef Australia is pulling out all the stops: the Mystery Box challenges are bigger and better, the guest chef line-up looks truly exciting with the likes of celebrity chefs Nigella Lawson and Gordon Ramsay, and the ingredients are as diverse as the series' contestants. This series looks to be the most multicultural yet, showcasing a very modern Australia in its choice of 24 contestants. In addition to 'true blue' Australians, we meet a Singaporean prison officer with a penchant for spice, a Mauritian boxer with an eye for detail, a Vietnamese DJ born in a refugee camp who can plate food like no other, a wonderfully down to earth Italian grandmother who cooks from the heart, as well as a Lebanese mum with a candy floss recipe that stops even Nigella in her tracks.

For seven months they are housed together, learning and competing daily through a series of challenges for a chance at the winner's prize. MasterChef Australia stands out in this regard in the realm of cooking and baking shows. It has over 60 episodes that are jam packed with emotion, 
tenderness, excitement, and showcases just plain good cooking. The show is a powerhouse of not only cooking, but also human emotion. After over 70 hours of footage, we can't help but feel attached and somehow invested. Plus, we keep coming back for more. The Australian version of MasterChef is of course part of a larger franchise (MasterChef UK and MasterChef USA), but it remains by far the version that is most watched. This can be attributed to its geniality and culture of food, as well as the way the contestants grow together. There is no delusion about the hard life of the catering business, and the three male judges hold the contestants to that. English born chef Gary Mehigan, restaurant critic Matt Preston, and third judge, chef George Calombaris, hold the show together well. They provide criticism and direction for when contestants get it wrong, they are hands-on, running kitchens in team challenges as well as judging, and genuinely love trying the wide variety of food served to them throughout the competition.

This year, the series showcases even more of Australia's indigenous foods, or 'bush tucker'. Ingredients like wattleseed, fingerlime, and lemon myrtle, which are native Australian foods that Aboriginal people previously utilised, are used in a Mystery Box challenge, a team challenge, and even as part of a challenge to make the best Australian canapés for HRH Prince Charles (green ants on a wattleseed baguette, Your Royal Highness?). While popular indigenous Chef Mark Olive gave a MasterChef 'Master cooking class' to contestants back in series 3, it seems a shame that not more indigenous chefs or indeed Aboriginal people are included in this tenth anniversary series, especially since indigenous chefs are currently carving a huge profile in the world of food.

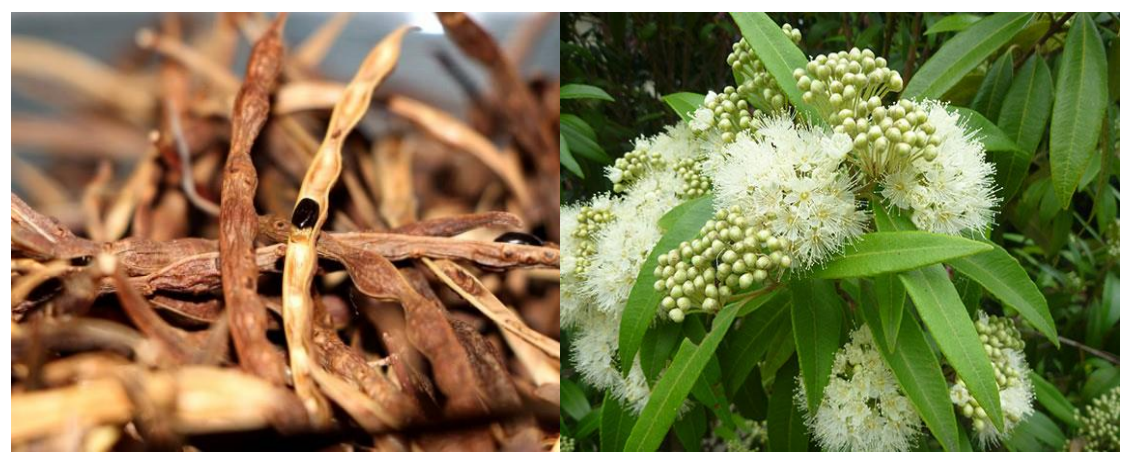

Wattleseed, Lemon Myrtle

Mark Olive said recently in an interview with the Australian Daily Telegraph that chefs around the world are curious about native ingredients, and that MasterChef did have 'a mystery box with indigenous herbs, which was great, but it should be on more than once a series'. Olive wants even 
more promotion of indigenous ingredients and has been teaching cookery to children in schools for over three decades in an attempt to do this. Mainstream chefs are certainly including these ingredients, but if not for the Aboriginal people who have been using them for thousands of years, little would be known about wattleseed or quandong. Many ingredients are also now being commercially grown due to their popularity, and these once basic indigenous ingredients are now seen as niche and trendy in high dollar restaurants across Australia. This ‘cultural commodification' is further seen in the struggles to keep multinationals from exploiting and patenting these 'superfoods'.

Other ethnic foods also make regular appearances from the contestants, many using their family's recipes or a technique they have learned at their mother's knee; innate knowledge that cannot necessarily be learned from books. It makes for tense judging from three white foodies, and one cannot help but wonder how they manage to get past awkward exchanges of 'but this is how my grandmother made it' and judge traditional dishes at all. But, it seems to work (unlike the recent fiasco this spring on MasterChef UK in which Malaysian-born Zaleha's chicken Rendang was criticised for not being 'crispy' enough by judge Gregg Wallace), and this series showcases some of the most fantastic cultural dishes seen so far.

Witnessing contestants learning how to harness the knowledge they arrive with is what really makes MasterChef Australia exciting. The process of narrowing down family-size curries to Michelin star dishes is phenomenal, and suddenly it is about more than just cooking; it's about the people and their relationships to food. It is a very exciting, multicultural anniversary series, though one cannot help but notice the stark absence of the first Australians in MasterChef Australia, even if their ingredients do make it onto our screens and into our recipes books.

MasterChef Australia starts in the UK on 29 August at 19:00.

Join the discussion below. 


\section{Tradition of 'Zwarte Piet' Racism or a Harmless Children's Celebration?}

Kate Vowles-Sørensen | Aarhus | 2018

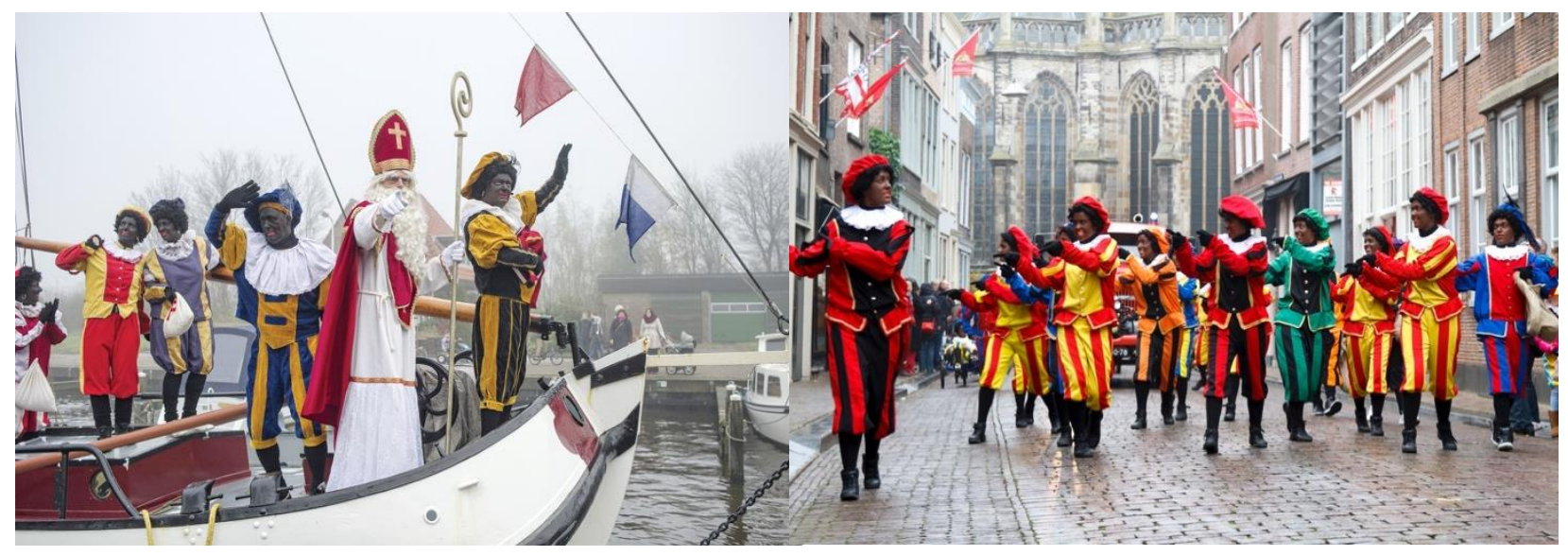

Sinterklaas' helper sparks clashes across the Netherlands and Belgium

As the holiday season approaches, Zwarte Piet (Black Pete) is making his appearance once again in the Netherlands and Belgium. The current debate in the Netherlands and Flanders regarding racist undertones in the depictions of Sinterklaas' (St. Nicholas') blackface helper, Zwarte Piet is most active through Twitter with the hashtags: \#kozp (kick out Zwarte Piet = kick out Black Pete) and \#zwartepietisracisme (Black Pete is racism). Additionally, protests upon Sinterklaas' arrival to the Netherlands (this year, November 17) were underway in 18 cities, sparking debate and violent clashes between pro- and anti-Zwarte Piet groups. Police have made multiple arrests over these clashes and attempted to control the 250 violent white supremacists in Eindhoven who gave Nazi salutes, and threw eggs and bananas at anti-Zwarte Piet protestors.

So, what is all this debate about? On Twitter, we see that the pro-Zwarte Piet camp claim that the character is black because he came down the chimney and is covered in soot. They maintain that the character is part of a children's festive tradition and is harming no one. Yet, as the anti-Zwarte Piet camp points out, how does the character gain a curly black afro, bright red lips and gold hooped earrings by coming down the chimney? Many Dutch Twitter users write how guilty they feel that their country is allowing this tradition to continue, arguing that it is white privilege and unacceptably racist. In fact, Zwarte Piet looks more like a blackface character from minstrel shows than a 'mischievous helper'. The tradition started in 1850 with a book by Jan Schenkman, an Amsterdam school teacher, 
called Saint Nicholas and His Servant. Once a servant who stuffed naughty children in a burlap sack, Zwarte Piet is now more of a helper to Sinterklaas, handing out sweets and presents to children and generally leading the many festivities around the Sinterklaas holiday. However innocently meant, it is clear that Zwarte Piet is now considered highly offensive. Many have campaigned for an end to the practice of blackface in the Sinterklaas celebrations, seeing it as a racist and colonial legacy, while others argue that it is a traditional and innocent children's celebration.

\#kozp slavery was a tradition too.

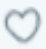

\section{Nov 17}

i am so ashamed of my countrry and of myself for ever thinking that this is okay. it's easy for us white people to say that it's 'just tradition' because or lives aren't affected by it. white privilege disgusts me and this racist event disgusts me \#zwartepietisracisme

\section{ENAR Europe $\$$ ENAREurope $\cdot$ Dec 14}

We can't stay silent anymore about racist \#zwartepiet. There are so many traditions in this world and not all traditions are things we should continue in a civilized society. \#zwartepietisracisme \#KOZP \#KickOutZwartePiet

\section{Nov 17}

It's incredible that some Dutch people still can't see that black facing is racism! \#ZwartePietlsRacisme

\section{Nov 30}

"it's not blackface, he's just black because of the soot from the chimneys!" \#zwartepietisracisme \#kickoutzwartepiet \#kozp \#McDonalds

The European Network Against Racism (ENAR) as well as the UN Committee on the Elimination of Racial Discrimination (CERD) have called on the Netherlands to review the character. In 2015, the UN Committee wrote that the character 'reflects negative stereotypes' and is 'a vestige of slavery', which are damaging to the dignity of both children and adults. The report went on to say that anti-Zwarte Piet protestors were being attacked violently and subjected to intimidation. It requested that the government investigate these incidences and suggested reviewing the character to make it more acceptable for all those who celebrate. Prime Minister Mark Rutte dismissed the recommendations and has continued to come under fire for not taking a stronger stance on the issue.

Some on Twitter see the debate about Zwarte Piet as a cover up for larger issues, such as changes in demographics, economic insecurity, lack of distinct migration policies, and the rise in nationalist, 
far-right politics. Pro-Zwarte Piet supporters see the attack on the tradition as one more thing that they have to change in order to accommodate others. They say it is going against their Dutch identity and cultural traditions. However, just because Zwarte Piet is tradition, does that make it right? AntiZwarte Piet groups complain that black children are coming home and asking their parents why they can't wash off their black skin, or are ashamed of who they are because they are 'dirty'. These groups are trying to raise awareness about the devastating effects the tradition of Zwarte Piet can have on the children who, incidentally, the celebration is meant to be for. Schools in Rotterdam, Amsterdam and Utrecht are taking these points seriously, and this year the Zwarte Piet characters have been changed to have soot on the cheeks rather than full blackface.

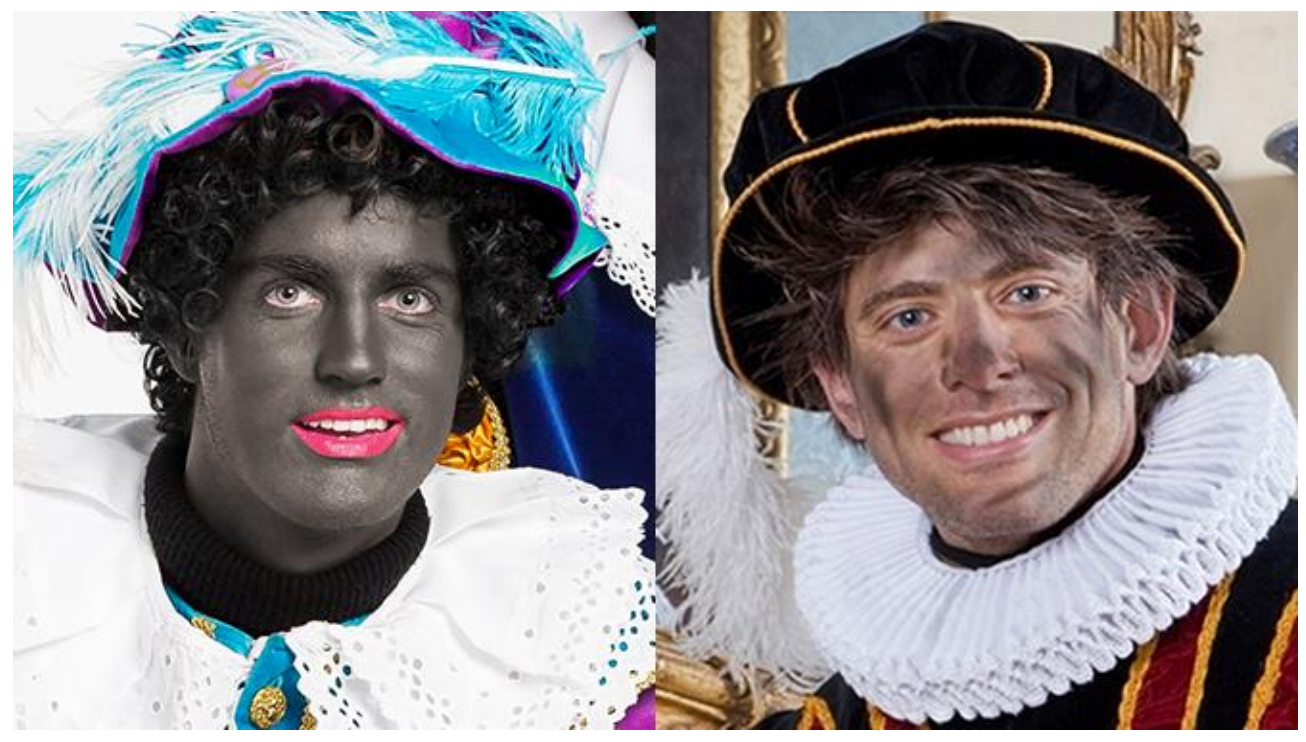

While these changes in big city schools, and the promises to not show full blackface Zwarte Piet characters from the TV broadcaster who reports the ceremony of Sinterklaas' arrival to the Netherlands are positive, the backlash against the anti-Zwarte Piet protestors both online and on the streets is less than encouraging. One spectator said that it was like seeing Dutch racism in full display. It is perhaps because the tradition is so closely connected to childhood memories and alleged Dutch cultural heritage it becomes so heated and emotional. Many solutions have been put forward including just having soot smudged on the face of the character, and doing away with the blackface paint, wig and gold earrings. In recent polls by I\&O, the number of Dutch who believe that Zwarte Piet should stay in his blackface form has decreased from $65 \%$ two years ago to about $50 \%$ this year. Forty percent of those questioned supported the new 'sooty-faced' Piet or other changes to his appearance. 
Yet, the lack of support from the Prime Minister and others in government, the violence and intimidation protestors are facing, and the division the debate has caused across the low countries is not an ideal example to be setting for the children of the Netherlands and Belgium. The institutionalised tradition of this character is starting to change, but only slowly and with much protest. We often think of the low countries as progressive, tolerant, open places, but this is one example of how they are not. Whatever the outcome, we can expect the controversy surrounding this outdated festivity to be back at the same time next year.

Let us know your thoughts in the comments below or join the debate on Twitter. 


\section{Case 1: Cultural appropriation of indigenous foods: Major borrowing by mainstream shows}

This case study discusses the appropriation of indigenous Australian food in the mainstream television programme MasterChef Australia during its tenth anniversary series in 2018. An analysis is made of the show's concepts concerning native food, concentrating on cultural appropriation and lack of agency. Using a review-style article in the online newspaper The Independent, an attempt is made to review the series and generate thought about the issues surrounding native food. Thus, while MasterChef Australia showcases a multicultural/ethnic and modern Australia through its contestants and recipes, indigenous Australians lack representation, and native foods are subtly appropriated while being given a trendy status. Firstly, the theories considered in this case revolve around Kulchyski's notion of 'cultural commodification' within the aspect of cultural appropriation. He argues that 'commodification is appropriation...to the extent that it involves a process of reshaping Aboriginal cultural productions so that they accord with the logic of the commodity form' (617). Everyday dishes become more fashionable when native ingredients are added. Haig-Brown also argues this point: 'commercial exploitation, from the use of Aboriginal art or images in advertising...to the use of traditional food or medicine plants, are blatant forms of such appropriation’ (930). Native foods are being exploited through patents by multinationals and being marketed as 'superfoods', effectively tapping into the health food trend at the expense of these ingredients. Additionally, Spivak's view of the subaltern voice and the Other's lack of agency is applied. The revelation of native foods is done by the dominant culture through a mainstream cooking programme. Thus, indigenous Australians are being spoken for about food connected strictly to their culture, and throughout 61 episodes in this series, they are mentioned only once.

Furthermore, by questioning why no indigenous chefs were invited for this series, an attempt is made to apply the above theories in the article. While using native foods may purely be seen as cultural borrowing, it is still called 'bush tucker' and seen as unique and trendy. This is why the issue of cultural appropriation in mainstream media is problematic. Scafidi states that the use of cultural products provides 'a starting point for recognition of the source community as well as a means of allowing outsiders a degree of participation in and appreciation of that community' (8). Arguably, any representation and exposure of native foods is positive, but the question of who benefits and for whom it is positive is crucial. 
In conclusion, without agency from indigenous Australians, 'bush tucker' merely becomes a fashionable trend. Consequently, ongoing struggles with multinational companies seizing control of these native foods via patents shows clear exploitation. As a by-product of colonialism, this mainstream appropriation must be recognised and addressed. Mainstream shows like MasterChef Australia can effectively do better when it comes to representing indigenous Australia.

\section{Case 2: Tradition of 'Zwarte Piet': Analysing the racist undertones of the 'Sinterklaas' festivities in the Netherlands and Belgium}

For those who consider the Netherlands and Belgium to be tolerant, progressive countries, the Zwarte Piet (Black Pete) tradition practiced during the Sinterklaas (St. Nicholas) holiday is shocking. The current debate surrounding the blackface character of Zwarte Piet in a celebration for children has become more heated and violent each year. Many anti-Zwarte Piet campaigns are attempting to remove the blackface character from the celebrations, while pro-Zwarte Piet camps intimidate and protest against these campaigners, showcasing their privilege by supporting institutionalised racism for the next generation. This argument, presented in an online op-ed-style article in The Guardian, aims to examine the debate through the Twitter hashtags \#kozp (kick out Zwarte Piet) and \#zwartepietisracisme (Zwarte Piet is racism), Dutch news, and other reactions. This case critically analyses the Zwarte Piet tradition and discusses the systemic racism engendered by its blackface practice.

The theories applied to this case include racism and institutionalized discrimination, but also notions about cultural heritage, history and identity. Hardt and Negri argue that racism has actually recently increased (191), and Bonilla-Silva states that 'the ideas endorsed by most whites today may sound like "racism lite" or may seem absent of racism altogether, they signify postmodern support of the racial status quo' (138-9). The arguments from the pro-Zwarte Piet campaigners reflect this quite clearly: the majority of white Dutch people do not see the tradition as racist, and their resistance to change in this regard reiterates the systemic racism of the celebration. As Bonilla-Silva points out, current racial practices 'tend to be covert, institutional, and apparently non-racial' (138).

This is synonymous with the bonds to culture and heritage. Many national cultures 'base membership on heritage and history that has been handed down through several generations' (Collier 54). This exemplifies how the character of Zwarte Piet, "part of the symbolic landscape representing Dutch culture, has become the centre of a representational battle on "Dutchness" and for the large 
majority of the Dutch population, Zwarte Piet 'is an essential part of its heritage and identity' (Rodenberg and Wagenaar 716-9). Therefore, many pro-Zwarte Piet campaigners see protests against the character as an attack on a Dutch cultural tradition and react strongly. This may also indicate why change regarding the character has been so challenging. As Mouffe argues, there is a true lack of access or indeed ability to challenge the establishment (82). Thus, multiple narratives of meaning are competing in this controversy, and many are not being heard due to intimidation, lack of response from the government, or merely by being outnumbered.

To conclude, adherence to this tradition is clearly outdated, and certainly more can be done by the low countries' governments. The intention of the article was to inform and persuade by posing questions based on facts and regarding both sides of the argument. While this institutionalised, racist character may never be completely removed, changes to his appearance and knowledge about the dangerous affects it can have on those in the social minority (especially children) are slowing spreading. 


\section{Works cited}

Bonilla-Silva, Eduardo. 'Color-blind racism.' White supremacy and racism in the post-civil rights era, Lynne Rienner, 2001, pp. 137-166.

Chopra, Tasneem. 'Why Gordon Ramsay is no match for my aunties'. SBS Life. 3 Aug. 2018, www.sbs.com.au/topics/life/culture/article/2018/08/03/why-gordon-ramsay-no-match-myaunties.

Collier, Mary Jane. 'Cultural identity and intercultural communication.' Intercultural communication: $A$ reader, edited by Larry A. Samovar and Richard E. Porter, 11th ed., Wadsworth, 1994, pp. 53-60. Committee on the elimination of racial discrimination. 'Concluding observations on the nineteenth to twenty-first periodic reports of the Netherlands'. CERD/C/NLD/CO/19-21. 28 August 2015, tbinternet.ohchr.org/Treaties/CERD/Shared20Documents/NLD/CERD_C_NLD_CO_19_ 21_21519_E.pdf.

Dutch News. 'Half of Dutch people prepared to accept changes to Zwarte Piet's appearance'. Dutch News, 3 Dec 2018, www.dutchnews.nl/news/2018/12/half-of-dutch-people-prepared-to-acceptchanges-to-zwarte-piets-appearance.

Garen, Micah, Marie-Helene Carleton, and Justine Swaab. 'Zwarte Piet: Black Pete is "Dutch racism in full display"'. Al Jazeera News, 27 Nov 2018, www.aljazeera.com/indepth/features/zwarte-pietblack-pete-dutch-racism-full-display-181127153936872.html.

Haig-Brown, Celia. 'Indigenous thought, appropriation, and non-aboriginal people'. Canadian Journal of Education, Vol. 33, No. 4 (2010), pp. 925-950, www.jstor.org/stable/10.2307/canajeducrevucan.33.4.925.

Hardt, Michael and Antonio Negri. 'Imperial sovereignty'. Empire, Harvard University Press, 2000, 183-204.

Kulchyski, Peter. 'From appropriation to subversion: Aboriginal cultural production in the age of postmodernism’. American Indian Quarterly, Vol. 21, No. 4 (Autumn, 1997), pp. 605-620, doi: $10.2307 / 1185715$.

Lemmens, Koen. 'The dark side of "Zwarte Piet": A misunderstood tradition or racism in disguise? A legal analysis'. The International Journal of Human Rights, 21:2, (2017), 120-141, doi: 10.1080/13642987.2016.1276448. 
Mouffe, Chantal. 'Current challenges to the post-political vision'. On the Political, Routledge, 2005, pp. 64-89.

Price, Jenna. 'MasterChef: Why this season is better'. The Sydney Morning Herald, 19 Jul. 2018, www.smh.com.au/entertainment/tv-and-radio/masterchef-why-this-season-is-better-20180719p4zsgu.html.

Roddam, Franc, creator. MasterChef Australia. Series 10, Shine Australia, 2018.

Rodenberg, Jeroen and Wagenaar, Pieter. 'Essentializing "Black Pete": Competing narratives surrounding the Sinterklaas tradition in the Netherlands', International Journal of Heritage Studies, 22:9, (2016), 716-728, doi: 10.1080/13527258.2016.1193039.

Saurine, Angela. 'How Aussie Chefs are making indigenous food cool'. The Daily Telegraph, 6 Jul. 2015, www.dailytelegraph.com.au/lifestyle/food/sydney-taste/how-aussie-chefs-are-makingindigenous-food-cool/news-story/d06022471d69e938946d3b4d3820d7c7.

Scafidi, Susan. Who owns culture? Appropriation and authenticity in American law. Rutgers University Press: 18 May 2005.

Spivak, Gayatri Chakravorty. 'Can the subaltern speak?' [1988]. The post-colonial studies reader, edited by Bill Ashcroft, Gareth Griffiths, and Helen Tiffin, Routledge, 1995. 


\section{Images}

'Health benefits of wattle seed'. Ayushology, 15 Dec 2017, ayushology.com/health-benefits-ofherbs/health-benefits-of-wattle-seed.

'Lemon myrtle essential oil' Essentially Australia, essentiallyaustralia.com.au/shop/lemon-myrtleessential-oil/?v=dd65ef9a5579.

'Meet MasterChef Australia’s 2018 contestants'. MasterChef Australia, 8 May 2018, goo.gl/images/1c4Xzb.

Post, Patrick. 'The arrival of Sinterklaas'. VQR, 24 Nov 2012, www.vqronline.org/who-zwarte-piet. 'Sooty faced Piets'. Dutch News, 14 Oct 2015, www.dutchnews.nl/news/2015/10/sooty-faced-pietswill-be-with-sinterklaas-on-official-arrival/.

'Wij willen met dit plaatje een discussie over Zwarte Piet op gang brengen'. De Speeld, 25 Oct 2016, speld.nl/2016/10/25/willen-plaatje-discussie-zwarte-piet-op-gang-brengen/. 